\title{
Description of Lutzomyia (Helcocyrtomyia) tolimensis, a new species of phlebotomine sandfly (Diptera: Psychodidae) from Colombia
}

\author{
María C Carrasquilla ${ }^{1,4} /{ }^{+}$, Leonard Munstermannn², Dairo Marín ${ }^{1,3}$, Clara Ocampo ${ }^{1}$, Cristina Ferro ${ }^{4}$ \\ ${ }^{1}$ Centro Internacional de Entrenamiento e Investigaciones Médicas, Cali, Colombia \\ ${ }^{2}$ Yale University School of Public Health, New Haven, CT, USA ${ }^{3}$ Universidad del Tolima, Ibagué, Colombia \\ ${ }^{4}$ Laboratorio de Entomología, Instituto Nacional de Salud, Bogotá, Colombia
}

\begin{abstract}
A description is presented of Lutzomyia tolimensis sp. nov., a new species of the subgenus Helcocyrtomyia, series sanguinaria. It was collected in dwellings, peridomestic environment and in nearby forest patches located in the foothills of the Andean Central Cordillera, where in 2004-2006 occurred the largest epidemic ever recorded of leishmaniasis in Colombia. The male of this species is differentiated from other members of the series sanguinaria based on the following combination of characters: (i) base of coxite with 0-3 subequal setae, (ii) spines of gonostyle organized in positions 2.1.2, (iii) spines inserted on distal half of gonostyle and (iv) relationship of alar indices. The female is recognized principally by the following characters: (i) palpomere V longer than III, (ii) length of labroepipharynx and (iii) relationship of the alar indices.
\end{abstract}

Key words: Phlebotominae - Lutzomyia - new species - Colombia

Within the subfamily Phlebotominae (Young \& Duncan 1994, Galati 2003), genus Lutzomyia Franca, 1924, the subgenus Helcocyrtomyia Barreto, 1962 has public health importance because four of its 36 known species have been incriminated as vectors of Leishmania: Lutzomyia ayacuchensis Cáceres \& Galati, 1988 and Lutzomyia peruensis (Shannon, 1929) of Leishmania peruviana (Cáceres 1996, Cáceres et al. 2004), Lutzomyia hartmanni (Fairchild \& Hertig, 1957) of Leishmania colombiensis (Kreutzer et al. 1991) and Lutzomyia tortura Young \& Rogers, 1984 of Leishmania naiffi (Kato et al. 2008). Furthermore, in Colombia where Lutzomyia ceferinoi (Ortiz \& Alvarez, 1963) was misidentified by Young and Morales (1987) as Lutzomyia erwindonaldoi (Ortiz, 1978) (Galati \& Cáceres 1994), it was found naturally infected in a leishmaniasis focus in Arboledas, department of Norte de Santander, with unidentified flagellate forms resembling Leishmania (Young et. al 1987). Eleven species of the subgenus have been reported in Colombia, distributed among the Andean, Amazonian and Pacific Coast regions (Bejarano 2006, Bejarano et al. 2010, Galati 2010). Four of the species recorded in Colombia are placed within the series osornoi: Lu. ceferinoi, Lu. erwindonaldoi, Lutzomyia osornoi (Ristorcelli \& Van Ty, 1941) and Lutzomyia strictivilla Young, 1979, and seven belong to the series sanguinaria: Lutzomyia cirrita Young \& Porter, 1974, Lutzomyia velezi Bejarano, Vivero \& Uribe, 2010, Lutzomyia sanguinaria (Fairchild

Financial support: NIH/ICIDR (U19 AI065866), NIH/FIC (D43 TW006589-02)

+ Corresponding author: mccarrasquilla@ufl.edu

Received 18 June 2012

Accepted 9 July 2012
\& Hertig, 1957), Lutzomyia scorzai (Ortiz, 1965), Lutzomyia sp. of Pichinde Young, 1979, Lu. tortura and Lu. hartmanni. No species of the series peruensis have been found in Colombia (Galati \& Cáceres 1994).

The most severe epidemic of cutaneous leishmaniasis ever recorded in Colombia occurred in 2004-2006 in Chaparral (Morales et al. 2004), a municipality lying at 1,000-2,000 $\mathrm{m}$ above sea level in the Andean foothills of the department of Tolima (Valderrama-Ardila et al. 2010). Lutzomyia longiflocosa was responsible of domestic transmission based on the distribution of cases by age group, abundance of phlebotomines inside houses and their blood meal source and natural infections with Leishmania (Morales et al. 2004, Ferro et al. 2011). Among the phlebotomines captured in the study area were three species of the subgenus Helcocyrtomyia Barreto 1962: Lu. ceferinoi, Lu. erwindonaldoi and the new species described herein.

\section{MATERIALS AND METHODS}

Phlebotomines were collected in the vereda (township) of Agua Bonita in Chaparral. The ecological characteristics of the region have been described by Valderrama-Ardila et al. (2010). Forest fragments, cropland and human dwellings were the predominant habitats in the veredas where the highest rates of Leishmania infection in humans were recorded.

The phlebotomines were sampled between April 2008-June 2009. CDC light traps were operated between 06:00 pm-06:00 am and placed indoors, in the peridomestic environment and in nearby forest patches; sand flies were aspirated from a Shannon trap between 06:00 p.m.-10:00 p.m. set in the peridomestic area.

Specimens were cleared in $10 \% \mathrm{KOH}$ for $10 \mathrm{~min}$ at approx $60^{\circ} \mathrm{C}$ and then immersed in saturated liquid phenol for 24-72 h. Permanent mounts were made on glass slides with a mixture of Canada balsam and liquid phenol. Species-discriminant characters were measured 
with an eyepiece micrometer in a Leitz Laborlux D microscope. All measurements are expressed in microns. The initial value represents the holotype (male) or allotype (female). Mean values \pm 1 standard deviation (SD) for the paratypes are shown in parentheses.

\section{RESULTS}

Lutzomyia (Helcocyrtomyia) tolimensis Carrasquilla, Munstermann, Marín, Ocampo \& Ferro, sp. nov. (Figs 1-10)

Diagnosis (male and female adults are described) - Lu. tolimensis is predominantly brown, with mesonotum, terminalia, vertex and occipitum dark brown.

Male (Figs 1, 5, 8-10) - Large phlebotomine sandfly, length approximately $3,090(3,306 \pm 200 ; n=9)$, including thorax and abdomen.

Head (Fig. 1): length $395(437.8 \pm 17.6 ; \mathrm{n}=9)$ including clypeus, width $376(407.4 \pm 18.1 ; n=9)$. Eyes large, $240(258.3 \pm 10.3 ; \mathrm{n}=9)$ long by $150(156 \pm 7.4$; $\mathrm{n}=9)$ wide. Interocular distance $83.5(91.4 \pm 6.8 ; \mathrm{n}=$ 9 ), equivalent to the diameter of four $(4 \pm 0.2 ; \mathrm{n}=9)$ facets. Interocular sutures not united with the interantennal suture. Interocular suture incomplete. Clypeus $121.8(132.0 \pm 9.4 ; \mathrm{n}=9)$ long bearing 21 setal scars. Length of labro-epipharynx $294.4(325.1 \pm 10.5 ; \mathrm{n}=7)$. Labial sutures forming a furca. Flagellomere lengths: I $387.2(434.9 \pm 39.0 ; n=9)$, II $162(178.3 \pm 7.8 ; n=9)$, III $159(172.2 \pm 8.9 ; \mathrm{n}=9)$, IV $150(159.8 \pm 9.3 ; \mathrm{n}=9), \mathrm{V} 144$ $(154.3 \pm 9.7 ; n=9)$, VI $138(144.2 \pm 8.6 ; n=9)$, VII 130.5 $(134 \pm 9.2 ; \mathrm{n}=8)$, VIII $127(120 \pm 8.3 ; \mathrm{n}=8)$, IX 105 $(117.9 \pm 9.8 ; n=8)$, X $96(111.2 \pm 9.7 ; n=8)$, XI $90(102.4$ $\pm 8.9 ; \mathrm{n}=7)$, XII $66(73.1 \pm 6.7 ; \mathrm{n}=7)$, XIII $63.4(63 \pm 4.7$; $\mathrm{n}=7)$, XIV $57(61.5 \pm 4.2 ; \mathrm{n}=7)$. Flagellomere I longer than labro-epipharynx. Ascoids simple and paired: internal and external ascoids implanted at same level (Fig. 8), except in flagellomere I where internal ascoid was more proximal than the external one. Distal prolongation extended beyond middle of flagellomere. End of ascoid on flagellomere II reached $0.62(0.62 \pm 0.03)(\mathrm{n}=3)$ distal portion of the flagellomere. Ascoids of flagellomere I arose before middle of segment. Ascoids of flagellomere XIV not seen. Papilla (Fig. 8) on flagellomere II inserted on the distal portion $0.71(0.73 \pm 0.026 ; n=3)$ of internal face of the segment; ascoids did not reach level of papilla. Length of palpomeres: PI $50.8(51.2 \pm 4.1 ; \mathrm{n}=9)$, PII $142.1(151.7 \pm 15.0 ; n=9)$, PIII $172.6(180.9 \pm 15.5 ; n$ =9), PIV $71.1(88.1 \pm 6.1 ; n=9)$ and PV $304.6 \pm 14.4(n=$ 6). One of the Palpomeres V is collapsed and the other is missing in the holotype. Palpal formula 1.4.2.3.5; in the ratio 1.00:2.96:3.53:1.72:5.95. Newstead's spines on internal surface of third palpal segment (Fig. 1). Pharynx unarmed. Widest part of pharynx bore some grooves. Length of pharynx $203(213.0 \pm 9.8 ; n=9)$, maximum width $45(44 \pm 3 ; n=9)$. Cibarium without teeth. Pigment patch well-defined and cibarial arch not discernible.

Thorax: scutum, scutellum, coxae, katepimere, katepisternon and part of anepisternum dark brown. Pleura with seven $(7.0 \pm 1.6 ; n=9)$ proepimeral setae and 14 $(17.7 \pm 2.5 ; n=9)$ superior anepistenal setae. Setae on anterior edge of katepisternum absent. Wing length 2,452.7
$(2,623.1 \pm 183.5 ; \mathrm{n}=8)$, maximum width $761.3(840.0 \pm$ $36.8 ; \mathrm{n}=8)$; length of vein sections: $\alpha 741.0(837.3 \pm 45.7$; $\mathrm{n}=8), \beta 223.3(241.9 \pm 19.3 ; \mathrm{n}=8), \gamma 284.2(339.1 \pm 37.7$; $\mathrm{n}=8), \delta 304.5(329.5 \pm 21.2 ; \mathrm{n}=8), \pi 151.2(144.4 \pm 15.3$; $\mathrm{n}=8)$ and R5 $1,424.1(1,605.0 \pm 52.5 ; \mathrm{n}=8)$ (Fig. 5).

Length of femora, tibiae, basitarsi and tarsi II + III $+I V+V$ : foreleg $909(1,084.3 \pm 44.5 ; \mathrm{n}=7), 1,621.1$ $(1,882.9 \pm 75.6 ; \mathrm{n}=7), 1,121.1(1,305.1 \pm 72.4 ; \mathrm{n}=7)$, $1,060.5(1,201.2 \pm 56.5 ; \mathrm{n}=7)$, midleg $848.4(952.3 \pm$ $55.6 ; \mathrm{n}=7), 1,787.7(1,993.3 \pm 115.3 ; \mathrm{n}=7), 1,166.6$ $(1,367.8 \pm 113.6 ; n=7), 1,045.4(1,209.8 \pm 60.9 ; n=7)$, hindleg $999.9(1,069.6 \pm 91.9 ; \mathrm{n}=5), 2,045.3(2,302.8$ $\pm 121.2 ; \mathrm{n}=5), 1,363.5(1,502.9 \pm 139.8 ; \mathrm{n}=7), 1,030.2$ $(1,269.6 \pm 89.2 ; \mathrm{n}=5)$.

Abdomen: length $2,514.9(2,599.1 \pm 171.3 ; \mathrm{n}=9)$ including genitalia. Coxite length $345.1(360.0 \pm 14.1$; $\mathrm{n}=9)$, maximum width $81(81.5 \pm 3.4 ; \mathrm{n}=9)$. Base of coxite with zero-three persistent subequal setae (Fig. 9), slightly shorter than width of coxite. Length of gonostyle $182.7(195.6 \pm 8.9 ; \mathrm{n}=9)$, maximum width $33(35.3 \pm 0.1$; $\mathrm{n}=9$ ). Gonostyle with five spines, arranged 2.1.2, with two apical spines implanted at same level, one upper external spine in basal portion $0.83(0.85 \pm 0.01 ; \mathrm{n}=9)$ and two basal spines on basal $0.59(0.61 \pm 0.01 ; \mathrm{n}=9)$. Paramere simple, base slightly widened, apex slightly inclined toward the coxite. Paramere: dorsal margin length $183(184.4 \pm 69.2 ; \mathrm{n}=9)$ and ventral margin $186(197.28$ $\pm 80.12 ; \mathrm{n}=9$ ). Two-thirds of dorsal margin covered with relatively long setae inclined toward coxite. Median area of ventral margin covered with setae, these being shorter than those found on dorsal part. Lateral lobe 268.4 (299.0 $\pm 10.6 ; \mathrm{n}=9$ ) long, extending beyond tip of paramere, but not passing apex of coxite. Aedeagus conical, slender and pigmented. Length of genital pump $132.6(140.7 \pm$ $8.7 ; n=9)$, length of genital filaments $381(406.3 \pm 50.3$; $\mathrm{n}=9$ ). Genital filaments slender and not modified at tips (Fig. 10). Cercus 210 (228.3 $\pm 10.8 ; n=9)$. Pavilion approximately two times length of piston.

Female (Figs 2-4, 6, 7) - General colouration as in male.

Head (Fig. 2): length $578(540.8 \pm 31.4 ; \mathrm{n}=9)$ including clypeus, width $466(447.6 \pm 19.4 ; \mathrm{n}=10)$. Eyes large, $300(289.2 \pm 14.2 ; \mathrm{n}=10)$ long by $165(170.4 \pm 8.1$; $\mathrm{n}=10)$ wide. Interocular distance $129(126.9 \pm 12.2 ; \mathrm{n}$ $=10)$, equivalent to diameter of $5.8(5.9 \pm 0.6 ; \mathrm{n}=10)$ facets. Interocular sutures not united with interantennal suture. Interocular suture incomplete. Clypeus 203 $(184.9 \pm 19.8 ; \mathrm{n}=10)$ long bearing $27(26.4 \pm 2.6 ; \mathrm{n}=6)$ setal scars. Length of labro-epipharynx $568.4(535.9 \pm$ $35.4 ; \mathrm{n}=10)$. Labial sutures forming a furca. Flagellomere lengths: I $496.1(497.3 \pm 18.7 \mathrm{n}=10)$, II $213(198.3 \pm$ $9.2 ; \mathrm{n}=10)$, III $216(192.3 \pm 9.3 ; \mathrm{n}=10)$, IV $198(181.0$ $\pm 8.8 ; \mathrm{n}=6), \mathrm{V} 195(175.0 \pm 10.8 ; \mathrm{n}=6)$, VI $180(169.0$ $\pm 11.6 ; \mathrm{n}=6)$, VII $165(158.4 \pm 14.0 ; \mathrm{n}=5)$, VIII 165 $(146.1 \pm 9.1 ; \mathrm{n}=5)$, IX $147(137.7 \pm 7.5 ; \mathrm{n}=5)$, X 138 $(133.9 \pm 9.4 ; n=4)$, XI $120(113 \pm 15.4 ; n=3)$, XII $90(87.5 \pm 2.3 ; \mathrm{n}=3)$, XIII $72(75 ; \mathrm{n}=2)$, XIV $66(60$; $\mathrm{n}=2$ ). Flagellomere I shorter than labro-epipharynx. Ascoids simple and paired: internal and external ascoids 
implanted at same level (Fig. 7), except in flagellomere $\mathrm{I}$, where internal ascoid was more proximal than external one. End of ascoid of flagellomere II reached $0.69 \pm$ $0.07(\mathrm{n}=4)$ distal portion of flagellomere. Ascoids of flagellomere I arise before middle of segment. Ascoids of flagellomeres XIII and XIV not seen. Papilla (Fig. 7) inserted on the distal portion $0.72 \pm 0.02(n=4)$ of the internal face of flagellomere II, ascoids not reaching level of papilla. Length of palpomeres: PI 78 (84.0 $\pm 14.9 ; \mathrm{n}$ =9), PII 234 (227.5 $\pm 18.2 ; \mathrm{n}=9)$, PIII $274.1(264.0 \pm$ 18.6; $\mathrm{n}=9)$, PIV $104(106.8 \pm 10.9 ; \mathrm{n}=9)$ and PV 342 $(329.9 \pm 21.5 ; \mathrm{n}=2)$. Palpal formula for allotype and paratypes 1.4 .2 .3 .5 , in the ratio $1.00: 3.00: 3.51: 1.33: 4.38$ (1.00:2.71:3.14:1.27:3.92). Newstead's spines covering internal surface of third palpal segment. Pharynx un- armed, bearing some grooves. Length of pharynx 263.9 $(263.4 \pm 19.6 ; \mathrm{n}=10)$, maximum width $105(103.5 \pm 9.1$; $\mathrm{n}=8$ ). Cibarium (Fig. 3) with 16 reduced anterior vertical teeth and four posterior teeth. Lateral teeth reduced. Pigment patch and posterior bulge well-developed and cibarial arch incomplete.

Thorax: pleura with seven $(6.8 \pm 0.8 ; \mathrm{n}=7)$ proepimeral setae and $15.7 \pm 0.5(\mathrm{n}=7)$ superior anaepisternal setae. Setae absent from anterior edge of katepisternum. Wing length 3,279.2 $(3,064.9 \pm 137.3 ; \mathrm{n}=10)$, maximum width $1,119.7(982.1 \pm 72.9 ; \mathrm{n}=9)$; length of the vein sections: $\alpha 1,066.4(983.1 \pm 57.2 ; \mathrm{n}=10), \beta 355.3(301.5 \pm$ $25.8 ; \mathrm{n}=10), \gamma 406(377.6 \pm 22.3 ; \mathrm{n}=10), \delta 446.6(406.0$ $\pm 28.7 ; \mathrm{n}=10), \pi 181.5(180.3 \pm 33.0 ; \mathrm{n}=10)$ and $\mathrm{R} 5$ $1,999.8(1,857.4 \pm 68.6 ; \mathrm{n}=10)$ (Fig. 4).
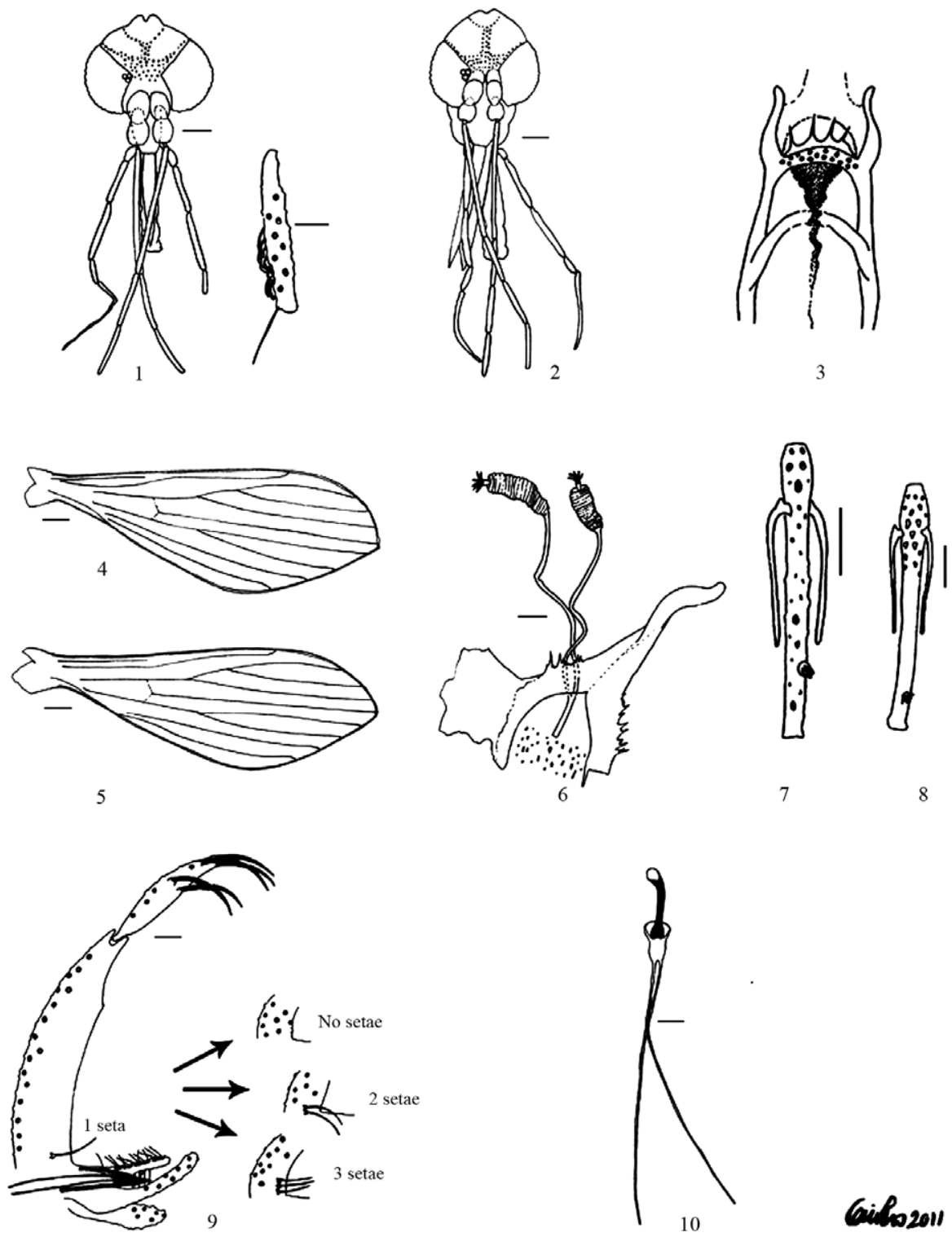

Lutzomyia (Helcocyrtomyia) tolimensis. 1: male head $(\mathrm{Bar}=87 \mu \mathrm{m})$ with detail of Newstead's spines in PIII $(\mathrm{Bar}=38 \mu \mathrm{m}) ; 2:$ female head $(\operatorname{Bar}=110 \mu \mathrm{m}) ; 3$ : female cibarium; 4: female wing $(\operatorname{Bar}=250 \mu \mathrm{m}) ; 5:$ male wing $(\operatorname{Bar}=178 \mu \mathrm{m}) ; 6$ : spermathecae $(\operatorname{Bar}=24 \mu \mathrm{m}) ; 7:$ female flagellomere II $(\mathrm{Bar}=47 \mu \mathrm{m})$; 8: male flagellomere II antennal segment $(\mathrm{Bar}=30 \mu \mathrm{m})$; 9: male terminalia $($ Bar $=37 \mu \mathrm{m})$ with detail of different number of setae that may be found in the coxite; 10: genital pump and filaments $($ Bar $=37 \mu \mathrm{m})$. 
Length of femora, tibiae, basitarsi and tarsi II + III $+I V+V$ : foreleg 1,151.4 $(1,141.3 \pm 56.4 ; \mathrm{n}=6), 1,999.8$ $(1,963.4 \pm 193.3 ; n=5), 1,332.2(1,418.0 \pm 279.7 ; n=5)$, $1,272.6(1,302.9 \pm 30.3 ; \mathrm{n}=5)$, midleg $1,030.2(1,022.7$ $\pm 75.3 ; \mathrm{n}=6), 2,181.6(2,085.7 \pm 72.8 ; \mathrm{n}=6), 1,484.7$ $(1,430.2 \pm 78.4 ; \mathrm{n}=5), 1,363.5(1,308.0 \pm 86.58 ; \mathrm{n}=6)$, hindleg 1,181.7 (1,151.4 $\pm 52.5 ; \mathrm{n}=3), 2,545.2(2,393.7$ $\pm 171.4 ; \mathrm{n}=2), 1,636.2(1,575.6 \pm 85.7 ; \mathrm{n}=2), 1,424.1$ $(1,393.8 \pm 85.7 ; \mathrm{n}=2)$.

Abdomen: spermathecae (Fig. 6) with approximately 21 annuli $(20.5 \pm 1.4 ; \mathrm{n}=5), 58.5(53.3 \pm 14.6 ; \mathrm{n}=5)$ long x $13.5(12.9 \pm 1.3 ; \mathrm{n}=6)$ wide, individual ducts: 150 $(141.0 \pm 7.9 ; \mathrm{n}=3)$ long $\mathrm{x} 3(3.1 \pm 0.2 ; \mathrm{n}=6)$, common duct: $34.0 \pm 3.5(n=3)$ long x $6.2 \pm 0.7$ wide $(n=4)$.

Type locality - Holotype male: Colombia, department of Tolima, Chaparral, vereda (township) of Agua Bonita (349'91"N 75³3'57"W) 21/07/08, D. Marín Coll.

Type data and depository - Holotype: permanent mount on a microscope slide (INS-7191) deposited at Laboratorio de Entomología, Instituto Nacional de Salud in Bogotá, Colombia. Allotype female and paratypes (9 males and 10 females) same data as holotype, but collected between April 2008-June 2009. Allotype, three paratype males and four paratype females deposited at Laboratorio de Entomología, Instituto Nacional de Salud, three paratype males and three paratype females deposited at the Yale Peabody Museum and at the Centro Internacional de Entrenamiento e Investigaciones Médicas.

Bionomics - Males and females were collected in dwellings, peridomestic environment and in nearby forest patches in the township of Agua Bonita located in the foothills of the Andean Central Cordillera in elevations between 1,460-1,704 m. Agua Bonita's main coverages were forest (43.2\%) followed by cultivation (23.7\%), shrubs (19.4\%) and grasslands (13.7\%). Crops include corn and sugar cane. Shrubs include shaded coffee plantation, thickets, small trees and cacao trees. According to Holdridge Life Zones, Agua Bonita township is located in premontane very humid forest (Valderrama-Ardila et al. 2010, Ferro et al. 2011).

Etymology - The new species is dedicated to the department of Tolima and its people.

\section{DISCUSSION}

According to the characteristics established by Galati and Cáceres (1994) for the subgenus Helcocyrtomyia, Lu. tolimensis sp. nov. has been introduced as a new member of the series sanguinaria because (i) the length of the clypeus was less than $1 / 3$ that of the head, (ii) in males the length of the coxite was greater than that of the lateral lobe and (iii) the coxite usually lacked a basal tuft of setae; if the tuft was present it consisted of up to six setae and occasionally a dispersed setal tuft. In females, the length of palpomere IV was equivalent to $1 / 2$ the length of palpomere III and palpomere $\mathrm{V}$ was less than or equal to $1.25 \mathrm{x}$ the length of palpomere III.

The male of Lu. tolimensis was differentiated from other members of the series sanguinaria as follows: (i) base of coxite with zero-three subequal setae, (ii) spines of gonostyle organized in positions 2.1.2, (iii) spines of gonostyle inserted on distal half of structure and (iv) length of alar indices. Position 2.1.2 of the five spines of the gonostyle permitted Lu. tolimensis sp. nov. to be distinguished from Lu. velezi, Lutzomia sp. of Pichinde, Lutzomyia kirigetiensis, Lutzomyia gonzaloi and Lu. hartmanni. It was also distinguished from $L u$. velezi by the length of the ascoids, which in this species reached the level of the papilla, whereas in Lu. tolimensis they were shorter. It was distinguished from Lutzomyia sp. of Pichindé by the $\delta / \beta$ ratio; in this species $\beta$ is longer than $\delta$, whereas in $L u$. tolimensis the converse is true. The new species differed from Lu. kirigetiensis, $L u$. hartmanni and Lu. gonzaloi based on the setae of the coxite: $L u$. kirigetiensis had four-six setae, one of which was slightly wider and longer than the others, Lu. hartmanni had one-four setae, one of which was longer than the others, Lu. gonzaloi had four or five setae at the base of the coxite and $\mathrm{Lu}$. tolimensis had zero-three setae on the coxite, all of the same length. Although Lutzomyia guderiani, Lutzomyia caceresi, Lu. tortura, Lutzomyia adamsi, Lu. scorzai, Lutzomyia monzonensis and Lu. cirrita also have five spines organized in positions 2.1.2, $\mathrm{Lu}$. tolimensis was differentiated from them by the following characteristics: (i) from $L u$. caceresi and $L u$. tortura by the length of palpomere V. In Lu. tolimensis the palpomere V $(304.6 \mu \mathrm{m} \pm 14.4)$ was clearly longer than palpomere III, $172.6 \mu \mathrm{m}(180.9 \pm 15.5)$; in Lu. caceresi and $L u$. tortura the palpomere $\mathrm{V}$ was only slightly longer than III. The lengths of the palpal segments V and III in Lu. caceresi were $168 \mu \mathrm{m}$ and $152 \mu \mathrm{m}$ respectively, and in $L u$. tortura the corresponding values were $150 \mu \mathrm{m}$ and $140 \mu \mathrm{m}$. (ii) The alar index $\delta$ in Lu. caceresi (115-196 $\mu \mathrm{m})$ was shorter than in Lu. tolimensis $304.5 \mu \mathrm{m}$ (329.47 \pm 21.2 ; $\min =304.5$, $\max =367.0$ ). (iii) The new species was separated from $L u$. tortura and Lu. adamsi by the length of the labro-epipharynx. Lu. tolimensis has a labro-epipharynx of $294.4 \mu \mathrm{m}(325.1 \pm 10.5 ; \mathrm{min}=294.4$, $\max =345)$ longer than that of Lu. tortura $(220 \mu \mathrm{m})$ and shorter than in $L u$. adamsi $(410 \mu \mathrm{m})$. Furthermore, $L u$. adamsi is clearly bigger and flagellomere I $(550 \mu \mathrm{m})$ is longer than in Lu. tolimensis, $387.2 \mu \mathrm{m}(434.9 \pm 39.0)$. (iv) $\mathrm{Lu}$. cirrita had 28-35 diffuse setae on the median part of the coxite and the genital filaments were five times longer than the genital pump. In Lu. tolimensis the genital filaments were approximately three times longer than the genital pump. (v) In Lu. sanguinaria, the aedeagus and genital filaments had truncated tips and the pavilion was approximately four times the length of the piston and the posterior basitarsus was subequal in length to the posterior femur. In Lu. tolimensis the pavilion is approximately twice the length of the piston and the posterior basitarsus is longer than the posterior femur. (vi) In Lu. scorzai two-three setae occur on the coxite and one was clearly stronger and longer than the other(s). (vii) The new species was separated from $L u$. guderiani and $L u$. monzonensis by the $\alpha / \delta$ ratio. In these two species $\alpha$ was twice $\delta$, whereas in Lu. tolimensis $\alpha$ is 2.3-2.7 times $\delta$. Furthermore, in Lu. monzonensis $\delta$ was twice $\beta$ and in Lu. tolimensis the $\delta / \beta$ ratio varied 
from 1.2-1.6. In Lu. guderiani the two basal spines were inserted on the basal half of the gonostyle whereas in $L u$. tolimensis all the spines were located on the distal part of this structure. Furthermore, Lu. monzonensis had threefour setae on the coxite. Lu. guderiani had zero-one seta and Lu. tolimensis had zero-three setae.

The female of $L u$. tolimensis differed from the other species in the following characteristics: (i) Lu. cirrita had a very elongated spermatheca and palpomere III was longer than V. In Lu. tolimensis palpomere $\mathrm{V}$ was longer than III. (ii) In Lu. hartmanni palpomere $\mathrm{V}$ was shorter than or equal to palpomere III and in Lu. sanguinaria the two palpomeres were the same length. Furthermore $L u$. sanguinaria had a long, carrot-shaped spermatheca and the hind basitarsus was shorter than or subequal in length to the hind femur; in Lu. tolimensis the hind basitarsus was longer than the hind femur and the spermatheca was not carrot-shaped. (iii) Females of Lu. gonzaloi, Lu. kirigetiensis and Lu. hartmanni were distinguible because in all three the labro-epipharynx was shorter than or subequal to $400 \mu \mathrm{m}$, whereas in Lu. tolimensis the labro-epipharynx measured $568.4 \mu \mathrm{m}(535.9 \pm 35.4)$. (iv) The alar index $\delta$ in Lu. guderiani $(460-610 \mu \mathrm{m})$ and in Lu. monzonensis $(497.2 \mu \mathrm{m} \pm 43.9)$ was longer than in Lu. tolimensis $(406.0 \pm 28.7 ; \min =355, \max =456)$. The $\alpha / \delta$ ratio in $L u$. guderiani varied from $1.8-2.0$ and in Lu. monzonensis it was 2.0, whereas in Lu. tolimensis a was 2.3-2.7 times $\delta$. In Lu. monzonensis, $\delta$ was 2-2.5 the length of $\beta$ and in $L u$. tolimensis the $\delta / \beta$ ratio varied from 1.16-1.61. (v) The new species was differentiated from Lutzomyia botella by the shape of the spermathecae and the length of the ducts; in Lu. botella the spermathecae were inflated and the individual ducts were shorter than the spermathecae. Lu. tolimensis did not have this spermatheca shape and the individual ducts were longer than the spermathecae. (vi) Lu. adamsi is larger, had a labroepipharynx of $620 \mu \mathrm{m}$ and a flagellomere I of $550 \mu \mathrm{m}$. In Lu. tolimensis the labro-epipharynx is shorter and the length of flagellomere I is $496.1(497.3 \pm 18.7) \mu \mathrm{m}$. Lutzomyia sp. of Pichinde differed because $\delta(320 \mu \mathrm{m})$ was subequal to $\beta(320 \mu \mathrm{m})$, whereas in $L u$. tolimensis $\delta$ was longer than $\beta$. In Lu. scorzai the tibia, basitarsus and tarsi II, III, IV and V of the anterior, median and posterior legs were shorter than in Lu. tolimensis.

\section{ACKNOWLEDGEMENTS}

To the Laboratorio de Entomología, Instituto Nacional de Salud, to the Department of Public Health of Tolima, and to the Hospital San Juan Bautista de Chaparral, to the technical assistance of Benjamin Pérez and Carlos Moreno, to Mabel Moreno, for her help in the field work, and to Camila Pizano, for the illustrations.

\section{REFERENCES}

Bejarano EE 2006. Lista actualizada de los psicódidos (Diptera: Psychodidae) de Colombia. Folia Entomol Mex 45: 47-56.
Bejarano EE, Vivero RJ, Uribe S 2010. Description of Lutzomyia velezi, a new species of Phlebotominae sand fly (Diptera: Psychodidae) from the department of Antioquia, Colombia. Mem Inst Oswaldo Cruz 105: 322-325.

Cáceres AG 1996. Especies de Lutzomyia (Diptera: Psychodidae, Phlebotominae) vectores de la "uta" en el Perú. Rev Peru Entomol 38: 23-26.

Cáceres AG, Villaseca P, Dujardin JC, Bañuls AL, Inga R, López M, Arana M, Ray DL, Arévalo J 2004. Epidemiology of Andean cutaneous leishmaniasis: incrimination of Lutzomyia ayacuchensis (Diptera: Psychodidae) as a vector of Leishmania in geographically isolated, upland valleys of Peru. Am J Trop Med Hyg 70: 607-612.

Ferro C, Marín D, Góngora R, Carrasquilla MC, Trujillo J, Rueda N, Marín J, Valderrama C, Alexander N, Pérez M, Munstermann LE, Ocampo CB 2011. Phlebotomine vector ecology in the major outbreak recorded of American cutaneous leishmaniasis in Colombia: indication of domestic transmission. Am J Trop Med Hyg 85: 847-856.

Galati EAB 2003. Classificação de Phlebotominae. In EF Rangel, R Lainson, Flebotomineos do Brasil, Fiocruz, Rio do Janeiro, p. 23-51.

Galati EAB 2010. Phlebotominae (Diptera, Psychodidae). Classificação, morfologia, terminologia e identificação de adultos: bioecologia e identificação de Phlebotominae, Apostila disciplina HEP 5752, Universidade de São Paulo, São Paulo, 126 pp.

Galati EAB, Cáceres A 1994. Descrição de Lutzomyia pallidithorax, sp. n. e de Lutzomyia castanea, sp. n. do Peru e análise cladística das séries do subgênero Helcocyrtomyia Barreto (Diptera, Psychodidae). Rev Bras Entomol 38: 471-488.

Kato H, Gómez E, Yamamoto Y, Calvopiña M, Guevara A, Marco J, Barroso P, Iwata H, Hashiguchi Y 2008. Natural infection of Lutzomyia tortura with Leishmania (Viannia) naiffi in an Amazonian area of Ecuador. Am J Trop Med Hyg 79: 438-440.

Kreutzer RD, Corredor A, Grimaldi Jr G, Grogl M, Rowton ED, Young DG, Morales A, McMahon-Pratt D, Guzman H, Tesh R 1991. Characterization of Leishmania colombiensis sp. n (Kinetoplastida: Trypanosomatidae), a new parasite infecting humans, animals and phlebotomine sand flies in Colombia and Panama. Am J Trop Med Hyg 44: 662-75.

Morales D, Castaño C, Lozano E, Vallejo H 2004. Descripción de la epidemia de leishmaniasis cutánea en Chaparral y San Antonio, 2003 y 2004. Inf Quinc Epidemiol Nac 9: 180-186.

Valderrama-Ardila C, Alexander N, Ferro C, Cadena H, Marín D, Holford T, Munstermann L, Ocampo C 2010. Environmental risk factors for the incidence of American cutaneous leishmaniasis in a sub-Andean zone of Colombia (Chaparral, Tolima). Am J Trop Med Hyg 82: 243-250

Young D, Duncan M 1994. Guide to identification and geographic distribution of Lutzomyia and sand flies in Mexico, the West Indies, Central and South America (Diptera: Psychodidae), Mem Amer Entomol Inst 54: 1-881.

Young DG, Morales A 1987. New species and records of phlebotomine sand flies from Colombia (Diptera: Psychodidae). J Med Entomol 24: 651-665.

Young DG, Morales A, Kreutzer RD, Alexander JB, Corrredor A, Tesh RB, Ferro de Carrasquilla C, de Rodríguez C 1987. Isolations of Leishmania braziliensis (Kinetoplastida: Trypanosomatidae) from cryopreserved Colombian sand flies (Diptera: Psychodidae). J Med Entomol 24: 587-589. 